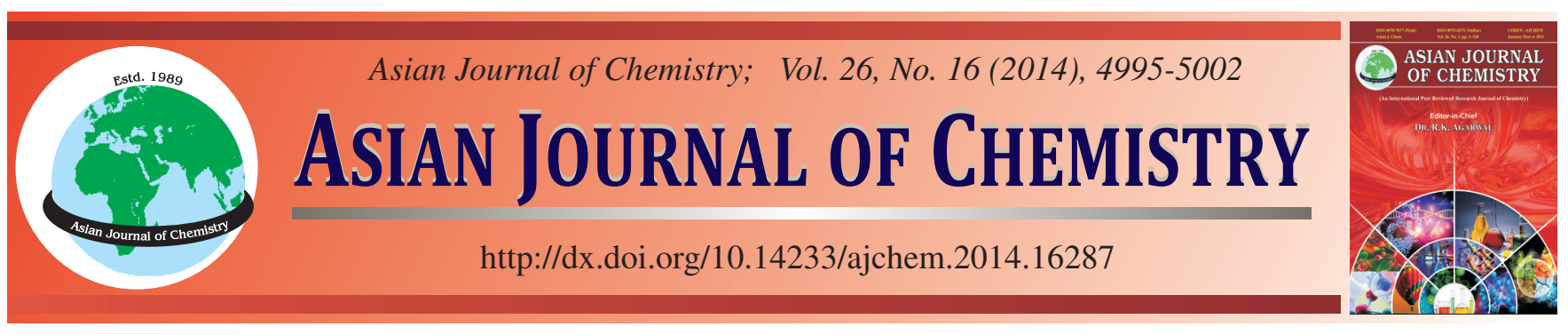

\title{
Emulsion Stability and Steady Shear Characteristics of Concentrated Oil-in-Water Emulsion Stabilized by Gelatinized Bambara Groundnut Flour
}

\author{
O. Adeyi ${ }^{1, *}$, D. IkHu-OMOREgBE ${ }^{1}$ and V. JideAni ${ }^{2}$
}

${ }^{1}$ Department of Chemical Engineering, Cape Peninsula University of Technology, Cape Town 7530, South Africa

${ }^{2}$ Department of Food Technology, Cape Peninsula University of Technology, Cape Town 7530, South Africa

*Corresponding author: E-mail: adeyioladayo350@yahoo.com

\begin{abstract}
Effect of sunflower oil and bambara groundnut flour concentrations on the stability and steady shear flow behaviour of concentrated sunflower oil-in-water $(\mathrm{o} / \mathrm{w})$ emulsion stabilized by gelatinized bambara groundnut flour dispersions was studied. Emulsion stability was studied using Turbiscan MA 2000 by observing changes in the average $\Delta$-backscattering flux (\%) at $20{ }^{\circ} \mathrm{C}$. The steady shear flow behaviours were also modeled by two rheological equations. Both bambara groundnut flour and sunflower oil concentration affected the emulsion stability and rheological behaviour. Increase in oil phase fraction and bambara groundnut flour concentration improved emulsion creaming and led to increase in the emulsion viscosity. Kinetics of destabilization showed that increase in sunflower oil and bambara groundnut flour concentration has profound effect on emulsion destabilization. For the steady shear flow models, both of the rheological models tested were found to predict the rheological behaviour of the emulsions. Herschel-Bulkley (H-B) predicted an increase in consistency index, yield stress and decrease in flow behaviour index with increase in the oil and bambara groundnut flour concentrations while Casson model revealed that all emulsions studied possessed yield stress and plastic viscosity which increased as sunflower oil and bambara groundnut flour concentration increased. However, high value of coefficient of determination $\left(\mathrm{R}^{2}\right)$ coupled with low root mean square error and standard error made Casson model a better predictor.
\end{abstract}

Keywords: Rheology, Bambara groundnut flour, Oil-in-water emulsion, Rheological model, Non-newtonian fluids.

\section{INTRODUCTION}

Emulsions are a class of dispersed systems that consist of two immiscible liquids, with one of the liquid dispersed as small droplets in the other called continuous phase ${ }^{1}$. Among important emulsion properties are emulsion stability and rheological behaviour. Emulsions are thermodynamically unstable and have tendency to break down overtime due to the difference in specific gravity between the oil droplets and medium usually water ${ }^{2}$. In many commercial emulsion formulations, polymers are often incorporated into the emulsions systems to modify the rheology of the continuous phase and to confer viscosity and yield value on the continuous phase ${ }^{3}$ thereby slowing down the gravitational separation of the droplets $^{2,4}$. A fast growing area in food emulsion technology research is finding new natural alternatives for improving the stability and rheological properties of emulsions. This is because consumers are demanding more natural products. Contributions of green banana pulp, okra extracts, flax seed and soybean to stability and rheology of oil-in-water emulsions have been documented ${ }^{5-7}$. Like other legumes (e.g. flax seed and soybean) bambara groundnut has recently been shown to possess stabilizing and emulsifying properties $^{8}$ and has been reported to stabilize oil in water emulsions ${ }^{9}$.

Bambara groundnut (Vignasubterranea (L.) Verdc) is an underutilized indigenous African legume grown primarily by subsistence farmers. Many researchers have studied the proximate compositions of this legume and on the average the bambara groundnut seeds contain $63 \%$ carbohydrate, $19 \%$ protein and $6.5 \%$ oil $^{10}$. The seed is regarded as a balanced food because it is rich in iron and the protein contains high lysine and methionine ${ }^{11}$. It was also reported that bambara groundnut flour contained $11.51 \%$ moisture content, $7.90 \%$ fat, $15.48 \%$ protein, $4.19 \%$ ash, $2.54 \%$ fiber and $58.38 \%$ carbohydrate $^{12}$. In another study conducted to determine the functional properties of bambara groundnut, it was unveiled that oil absorption capacity (OAC) of bambara groundnut flour was high which could be due to high content of hydrophobic proteins. The foaming capacity (FC) of bambara groundnut was reported as $72 \%$ and high emulsion capacity of $83 \mathrm{~g} / \mathrm{oil}$ protein, respectively ${ }^{13}$. Oil-gelatinized bambara groundnut flour emulsion is a novel "green" emulsion system that has potential applications in food industries but whose stability and rheological data have never been reported in the literature. 
Rheological data of emulsions are necessary to evaluate their behaviour during storage, in selection and operations of equipment involved in handling, mixing and pipe line transportation and in overall plant design ${ }^{3}$. The ability to control the rheological properties of emulsions depends on the quantitative understanding of the relationship between the rheology, composition and microstructure ${ }^{14}$. However, the precise nature of the equation that will be used to describe the rheological properties of a given emulsion system will depend on the characteristics of the system such as dispersed phase fraction, droplet interactions and continuous phase rheology ${ }^{15}$. Therefore predicting the rheological properties of emulsions still remains one of the most challenging and complicating problems in material and fluid sciences ${ }^{16}$.

The objectives of this work are to (1) prepare oil-in-water $(\mathrm{o} / \mathrm{w})$ emulsions using bambara groundnut flour as the sole emulsifying composition; (2) evaluate the effect of bambara groundnut flour and oil concentration on the stability and rheology of sunflower oil-in-water emulsion (3) investigate the suitability of two classical rheological models on the flow behaviour of the emulsions; (4) select the most appropriate flow model based on high coefficient of determination $\mathrm{R}^{2}$, low root mean square error and low standard error.

\section{EXPERIMENTAL}

Dried bambara groundnut of brown variety was purchased from Triotrade Gauteng CC, South Africa. The dried groundnut was milled into flour using a hammer mill and screened on 90 $\mu \mathrm{m}$ sieve. The screened flour (bambara groundnut flour) was gelatinized and used to stabilize the o/w emulsion. A commercial brand of $100 \%$ sunflower oil which was purchased from a local supermarket was used as the hydrophobic dispersed phase in this work without any further purification. Milli-Q water was used in the preparation of all the emulsions.

Emulsion preparation: Emulsions were prepared from a dispersed phase and a continuous phase. The dispersed phase consisted of SFO and continuous phase was gelatinized bambara groundnut flour dispersion. bambara groundnut flour dispersions of specific concentrations were prepared by dispersing measured amount of bambara groundnut flour [5-7 \% (w/w)] in known quantity of Milli-Q water. The resulting dispersions were gelatinized at a temperature of $84{ }^{\circ} \mathrm{C}$ for 10 min with constant stirring. The resulting gelatinized bambara groundnut flour dispersions (GBGNFD) were weighted in order to ascertain the amount of water loss during gelatinization. Water loss during gelatinization was compensated for by adding Milli-Q water to the gelatinized bambara groundnut flour dispersion, stirred and allowed to cool down to $20^{\circ} \mathrm{C}$. Measured quantities of sunflower oil [30-40\% (w/w)] were added into the gelatinized bambara groundnut flour to achieve different oil concentrations. No additives were added to either the hydrophobic or the hydrophilic phase. Emulsions (100 g) was made by homogenizing sunflower oil and gelatinized bambara groundnut flour using an Ultra Turrax T-25 homogenizer (IKA, Germany) at $11000 \mathrm{rpm}$ for $10 \mathrm{~min}$ without thermal control. Microstructure of the emulsions was analyzed immediately after emulsion preparation. Microstructural characterization was carried out in terms of droplet size and droplet size distribution and these were determined via microscopy. Image processing and further analysis was carried out using public domain software image J v1.36b (http://rsb.info.nih.gov/ij/) ${ }^{17,18}$. A substantial number of droplets were counted in order to obtain statistical estimate of the oil-droplet diameters and oil droplet size distribution in each sample. Droplet size frequency distributions were computed using MS-Excel (MicrosoftTM Excel 2007) ${ }^{19}$.

Optical characterization of emulsion stability: The stability of oil-in-water emulsions stabilized with bambara groundnut flour was monitored by using Turbiscan MA 2000 which was manufactured by Formulaction (France). The vertical scanner is made up of a light source which is an electro luminescent diode in the near infra-red $(\lambda=850 \mathrm{~nm})$ and two synchronous optical sensors namely transmission detector and backscattering detector. In principle, during optical scanning, the light passes through the dispersion and both the transmission and backscattering detectors receive light transmitted through the sample at an angle of $180^{\circ}$ and light backscattered by the sample at an angle of $45^{\circ}$ from the incident light respectively. $6 \mathrm{~mL}$ of bambara groundnut flour stabilized emulsion samples were introduced in a cylindrical glass cell and inserted into Turbiscan MA 2000. The optical reading head of the machine scans the whole length of the sample and acquires both the transmission and backscattered data every $40 \mu \mathrm{m}$ and every $30 \mathrm{~min}$ for $6 \mathrm{~h}$. The analysis of emulsion stability was carried out by observing the variation of backscattering profiles only over time because of the opaque nature of the emulsion samples since the transmission flux was nil. The stability or instability of the dispersion was observed and evaluated by conducting repeated multiple scans, each one providing a curve and all curves were overlaid on one graph to show stability or otherwise of the dispersion over time.

Rheological properties: All rheological tests were made in a shear rate controlled rheometer (Rheolab MC 1, Physica Inc., Stuttgard Germany). Samples were carefully transferred into rheometer cup and allowed to equilibrate for $10 \mathrm{~min}$ before shearing test proceeded. Emulsion viscosity was measured over a shear rate range of $750-40 \mathrm{~s}^{-1}$. The test temperature was maintained at $20^{\circ} \mathrm{C}$ and the test geometry was coaxial cylinder geometry conforming to Z3 DIN (bob radius: $12.5 \mathrm{~mm}$ : length $37 \mathrm{~mm}$ : cup radius: $13.5 \mathrm{~mm}$ ). All measurements were performed in triplicates.

Data analysis and modeling: All tests were conducted in triplicates. Mean and standard deviation were calculated using IBM SPSS version 21 software. Curve fitting was performed using the solver function in Microsoft Excel adopting the generalized reduced gradient (GRG2) nonlinear optimization code to determine the rheological parameters. The best fit line with minimum sum of square errors (SSE) was used as the sole criterion during curve fitting. The goodness of fit, $\mathrm{R}^{2}$ was calculated as $\mathrm{R}^{2}=1-\frac{\mathrm{SSE}}{\mathrm{SST}}$, where SST is the total corrected sum of square ${ }^{20,21}$. The best fit model was selected on the basis of coefficient of determination $\mathrm{R}^{2}$, root mean square error (RMSE, Eq. 1) and standard error (SE, Eq. 2).

$$
\operatorname{RMSE}=\left[\frac{\Sigma\left(\mathrm{Y}_{\mathrm{m}}-\mathrm{Y}_{\mathrm{c}}\right)^{2}}{\mathrm{n}}\right]^{1 / 2}
$$




$$
\mathrm{SE}=\left[\frac{\Sigma\left(\mathrm{Y}_{\mathrm{m}}-\mathrm{Y}_{\mathrm{c}}\right)^{2}}{\mathrm{n}-1}\right]^{1 / 2}
$$

where $\mathrm{Y}_{\mathrm{m}}$ is the measured value, $\mathrm{Y}_{\mathrm{c}}$ is the calculated value for each data point and $\mathrm{n}$ is the number of observations $\mathrm{s}^{22,23}$. Experimental flow data were evaluated and fitted according to the rheological models of Herschel-Bulkley Eq. (3) and Casson model Eq. (4).

$$
\begin{gathered}
\tau=\tau_{\mathrm{o}}+\mathrm{K} \gamma^{\mathrm{n}} \\
\tau^{0.5}=\tau_{\mathrm{oc}}^{0.5}+\mathrm{k} \gamma^{0.5}
\end{gathered}
$$

where, $\tau$ is the shear stress, $\tau_{0}$ is the yield stress, $\gamma$ is the shear rate, $\mathrm{K}$ is the consistency coefficients, $\mathrm{n}$ is the flow behaviour index, $\tau_{\mathrm{oc}}^{0.5}$ is the Casson yield, and $\mathrm{k}$ is the plastic viscosity ${ }^{23,24}$.

\section{RESULTS AND DISCUSSION}

Effect of gelatinized bambara groundnut flour and SFO on particle size distribution: Fig. 1 shows the oil droplet size distribution of all the studied emulsions. Fig. 1a, b and c are the oil droplet size distribution of freshly prepared emulsions stabilized with 5, 6 and $7 \%$ (w/w) GBGNFD, respectively. Oil droplet size of the emulsions are expressed in terms of volume surface mean diameter $\mathrm{d}_{3,2} \cdot \mathrm{d}_{3,2}$ is the volume-surface mean diameter or the Sauter-diameter of the emulsion samples and it provides information regarding the mean diameter where most of the particles fall ${ }^{25,26}$. The oil-droplet size distribution shows that both the bambara groundnut flour and SFO concentrations clearly affected the oil-droplet size. The volume-surface mean diameter, $\mathrm{d}_{3,2}$ of bambara groundnut flour emulsions studied was in the range of 2.80-5.35 $\mu \mathrm{m}$. The set of emulsions stabilized with $5 \%(\mathrm{w} / \mathrm{w})$ bambara groundnut flour recorded the highest $(4.05-5.35 \mu \mathrm{m})$ while emulsions stabilized with $7 \%(\mathrm{w} / \mathrm{w})$ recorded the least oil droplet size diameters (2.80$3.45 \mu \mathrm{m})$. As expected, there was an increase in oil droplet size with an increase in dispersed phase (SFO) concentration for all bambara groundnut flour concentration studied. Similar trend were reported for soybean-oil-in water emulsions? Although the increase in $\mathrm{d}_{3,2}$ was moderate, for example $\mathrm{d}_{3,2}$ for emulsions containing 30,35 and $40 \%(\mathrm{w} / \mathrm{w})$ stabilized with $5 \%(\mathrm{w} / \mathrm{w})$ bambara groundnut flour are 4.05, 4.53 and $5.35 \mu \mathrm{m}$, respectively. The effect of bambara groundnut flour concentration on oil-droplet size was also significant. With an increase in the bambara groundnut flour concentration, the $\mathrm{d}_{3,2}$ decreases. As an example the $\mathrm{d}_{3,2}$ of the emulsions containing $40 \%$ (w/w) sunflower oil, stabilized with 5, 6 and $7 \%$ $(\mathrm{w} / \mathrm{w})$ are $5.35,3.91$ and $3.45 \mu \mathrm{m}$. The decrease in the particle size with the addition of polymer has been explained to be due to an increase in viscosity of the continuous phase of the emulsion. For a given speed of the homogenizer, the shear stresses are higher when the viscosity of the continuous phase of the emulsion is high and hence finer droplets are produce in the mixer ${ }^{3}$.

Emulsion stability: Effect of bambara groundnut flour $(5-7 \% \mathrm{w} / \mathrm{w})$ and sunflower oil $(30-40 \% \mathrm{w} / \mathrm{w})$ were investigated on emulsion stability. Emulsion stability refers to the ability to resist changes in its properties through time ${ }^{27}$. The backscattering (BS) profile as function of tube length for bambara groundnut flour stabilized emulsions were analyzed for emulsion stability because all the emulsion samples remained fully turbid during the period of scanning. Representative backscattering profiles and their corresponding reference mode display are shown in Figs. 2 and 3. All emulsions showed similar backscattering profiles and the initial averaged backscattering value along the entire tube ranged from 91.27 to $96.15 \%$. For all the studied emulsions, backscattering was highly dependent on both the bambara groundnut flour and sunflower oil concentrations. Backscattering tended to increase with an increase in bambara groundnut flour and sunflower oil concentration. For example emulsion samples containing $30 \%$ (w/w) sunflower oil stabilized with 5, 6 and $7 \%(\mathrm{w} / \mathrm{w})$ bambara groundnut flour have average initial backscattering mean values of 91.27 , 92.71 and $95.29 \%$, respectively. The same trend of increase was observed in emulsions containing 35 and $40 \%$ sunflower oil stabilized with 5, 6 and $7 \%(\mathrm{w} / \mathrm{w})$ bambara groundnut flour. The initial backscattering profiles gives information of the microstructure of the recently prepared emulsions ${ }^{27}$ and a relation between $\mathrm{BS}_{\text {avo }}$ and $\mathrm{d}_{3,2}$ has been found in soy stabilized emulsion $^{28}$. Backscattering is a parameter that is directly dependent on the droplet mean diameter and oil volumetric fraction $^{29}$. In other to study the global stability of the bambara groundnut flour stabilized emulsion, backscattering profiles were analyzed at room temperature of $20^{\circ} \mathrm{C}$ and at different storage times to gain insights into the destabilization kinetics. These profiles constitute the macroscopic fingerprint of emulsion samples at a given time ${ }^{29}$. All the studied emulsions
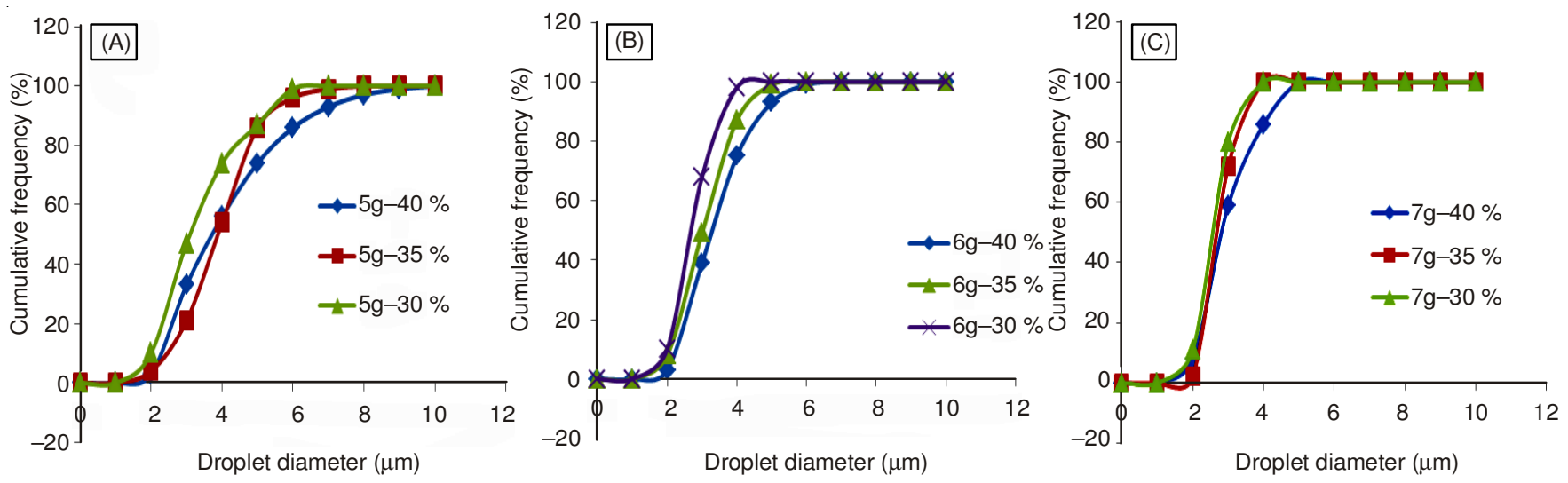

Fig. 1. Particle size distribution of emulsions stabilized with bambara groundnut flour 

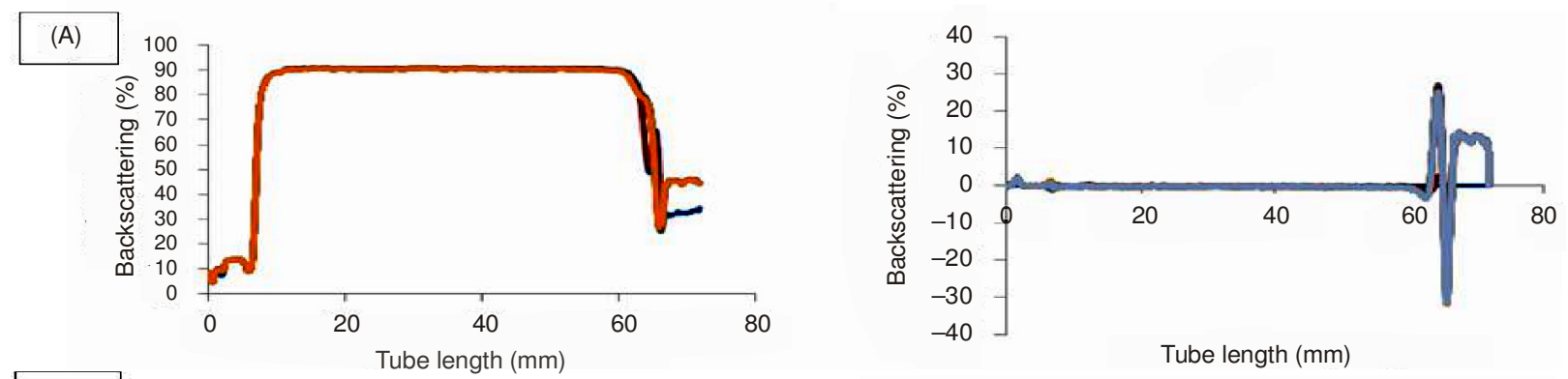

(B)
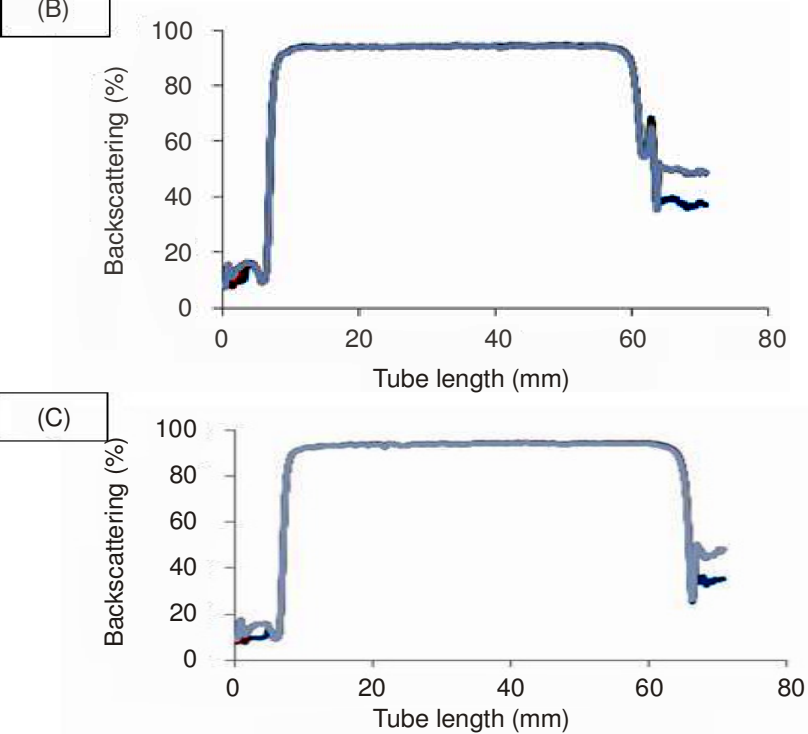
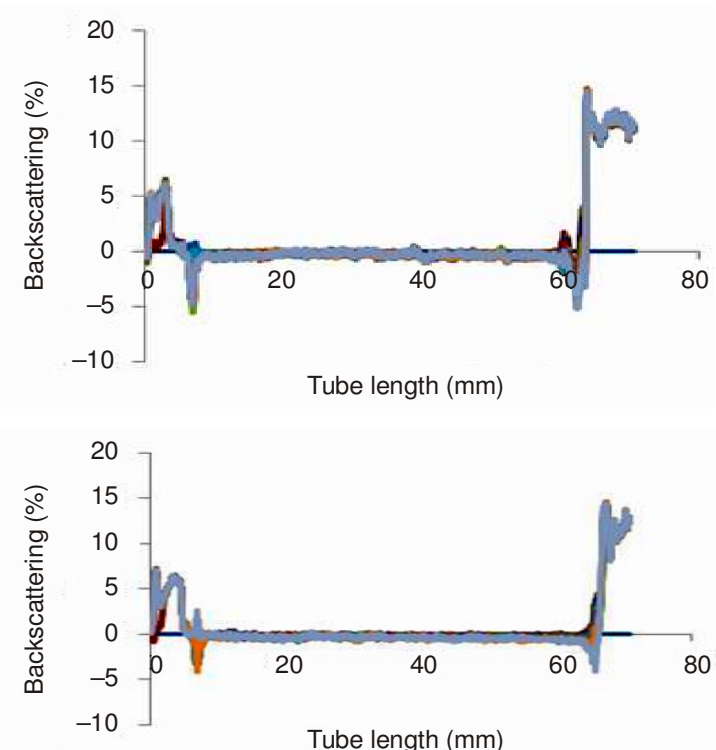

Fig. 2. Changes in backscattering profile (BS \%) as a function of sample height with storage time of bambara groundnut flour (5 \% (w/w)) stabilized emulsion (a) $30 \%$ SFO (b) $35 \%$ SFO (c) $40 \%$ SFO

$(\mathrm{A})$

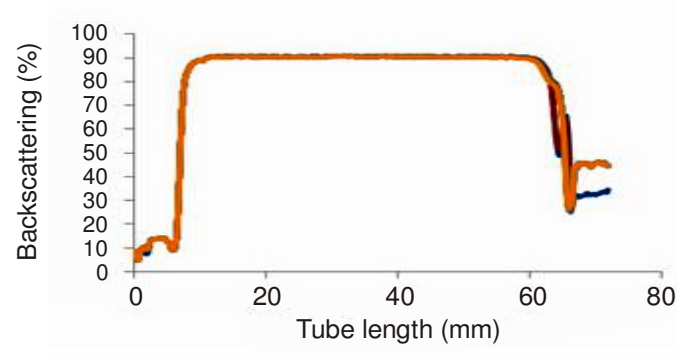

$(B)$

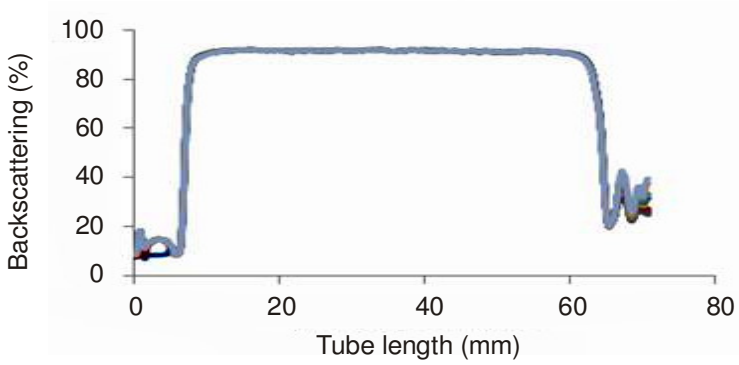

$(\mathrm{C})$

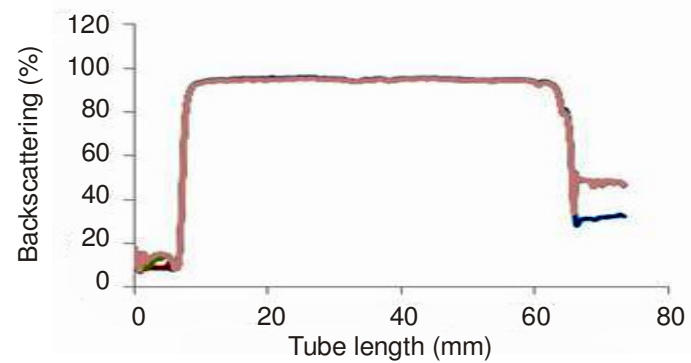

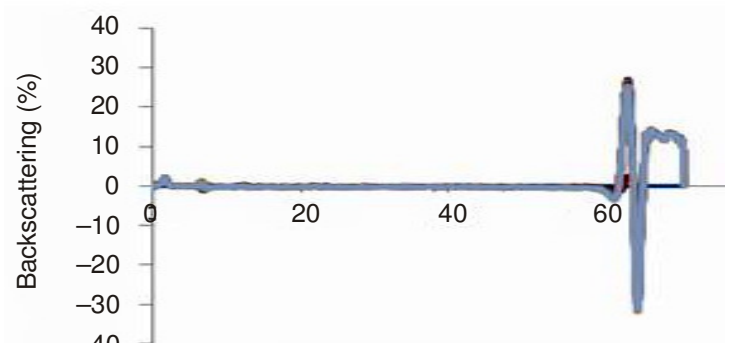

Tube length $(\mathrm{mm})$
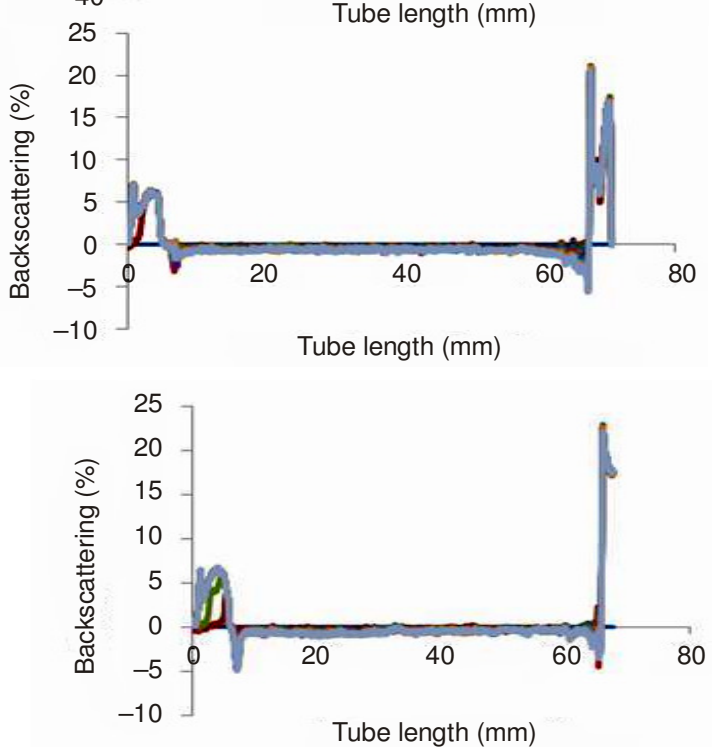

Fig. 3. Changes in backscattering profile (BS \%) as a function of sample height with storage time of emulsion containing $30 \%$ (w/w) SFO stabilized with (a) $5 \% \mathrm{w} / \mathrm{w}$ (B) $6 \% \mathrm{w} / \mathrm{w}$ (C) $7 \% \mathrm{w} / \mathrm{w}$ bambara groundnut flour 
showed similar multiple destabilization mechanism as evident from the backscattering-profile. The backscattering profiles for all the formulations showed a peak at the bottom of the tube between 0-20 $\mathrm{mm}$ zone when displayed in the reference mode.

The peak is attributed to a destabilization phenomenon called creaming and there was also a noticeable decrease in the average backscattering along the whole length of the tube, which is indicative of flocculation and or coalescence. In other study the effects of bambara groundnut flour and sunflower oil concentration, phenomenon that was prevalent and occurred repeatedly through particle size variation such as flocculation and coalescence in the emulsion samples were quantified. The variation in backscattering in the $20-40 \mathrm{~mm}$ zone with storage time was determined and it is as detailed in Fig. 4. All the destabilization kinetics followed the same trend with emulsions containing 30 and $40 \%(\mathrm{w} / \mathrm{w})$ sunflower oil concentration being the least and most affected respectively. It is clear from Fig. 4 that both bambara groundnut flour and sunflower oil affected the mechanism of destabilization.

Increase in bambara groundnut flour concentration improves stability for all dispersed phase concentrations, while increase in oil concentration increased destabilization of the studied emulsion.

Rheology of gelatinized bambara groundnut flour dispersion: Fig. 5 shows the plots of apparent viscosity $v s$. shear rate for three different gelatinized dispersions of bambara groundnut flour. All the bambara groundnut flour dispersions $(5,6$ and $7 \%)$ studied are non-Newtonian fluids. The viscosity of all the bambara groundnut flour dispersions tended to decrease as the shear rate increases showing a marked shear thinning which is indicative of structural destruction. At any given shear rate of our study, it was observed that the viscosity of GBGNFD increased with an increase in concentration of bambara groundnut flour indicated by upward shift of the curve (Fig. 5). This could be connected to an increase in the cross-links (gel formation) in the structure of the dispersions as the concentration increases, therefore requiring much more forces to disrupt the structure. Gelation in legume flours takes place more readily at higher protein concentration because of the greater intermolecular contacts during heating ${ }^{30}$.

A number of studies conducted on the rheological behaviour of biopolymer dispersions (predominantly gelatinized starches) have revealed that most parts exhibit pseudoplastic flow behaviours and that starch granule mass fraction plays an important role ${ }^{31}$.

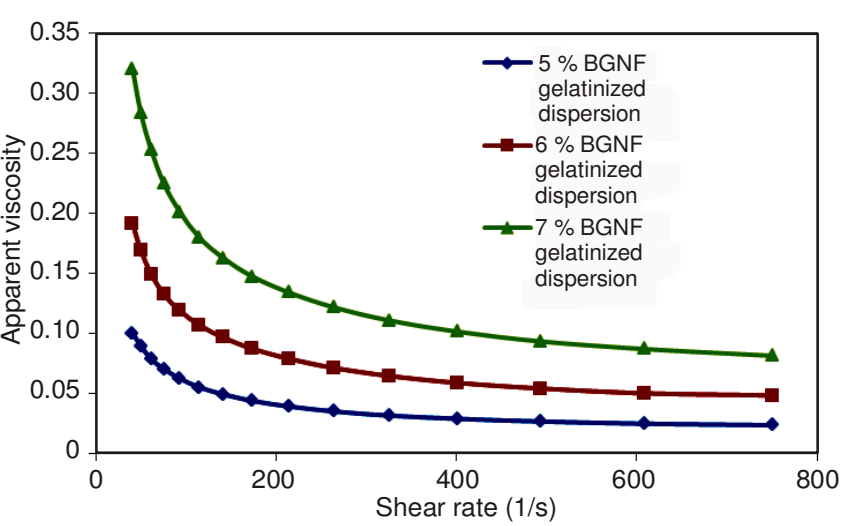

Fig. 5. Apparent viscosity as a function of shear rate for dispersions of bambara groundnut flour

Rheology of sunflower oil-in-water emulsions stabilized by gelatinized bambara groundnut flour dispersion: Flow curves of the studied emulsions as a function of SFO concentration [30-40\% (w/w)] and bambara groundnut flour concentration $[5-7 \%(\mathrm{w} / \mathrm{w})]$ are as presented in Fig. 6. All the emulsions depicted non-Newtonian behaviour since the viscosities of all the emulsions are not constant for all shear rate range. The emulsions flow curves were similar in shape to that of the bambara groundnut flour dispersions. Apparent viscosity of the emulsions decreased with increased shear rate, indicating a pseudoplastic behaviour due to progressive disruption of the flocs when the shear stress was increased ${ }^{2,32}$. This behaviour could be explained by the molecules structural breakdown generated and the increased constituent alignment ${ }^{33}$.

Small hydrodynamic flocs at low shear rate are not able to disrupt flocs and as an effect of increasing the shear rate, the hydrodynamic forces dominate and disrupt the flocs causing a reduction in viscosity ${ }^{1,34,35}$. The apparent viscosities of emulsions increased slowly initially as there was no significant difference between the flow curves of all the emulsions with $30 \%(w / w)$ oil concentration and flow curves of their corresponding bambara groundnut flour dispersions of 5, 6 and $7 \%(\mathrm{w} / \mathrm{w})$. As the oil-phase fraction (concentration) increased, the oil droplets come into close proximity then dispersions became more flocculated and viscosity increased. Consequently, flow curves shifted upwards to higher viscosities due to the increase in packing fraction of oil droplets. Increase in dispersion's viscosity has been related to droplet flocculation because the effective volume fraction of the particles in the system is increased due to the presence of the continuous phase trapped between the droplets in the flocs ${ }^{1,2,35,36}$. This result is
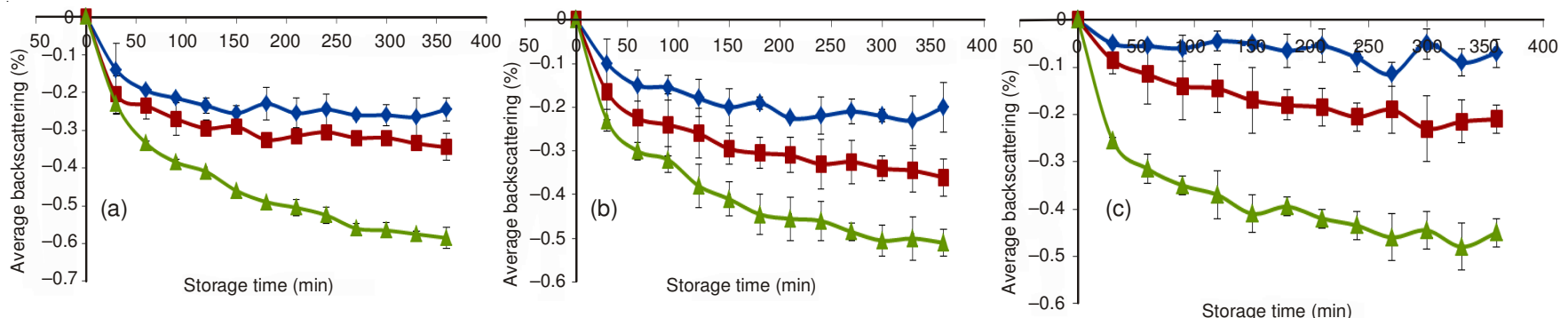

Fig. 4. Variation in backscattering in the $20-40 \mathrm{~mm}$ zone monitored over 360 min for sampled stored in quiescent condition at $20{ }^{\circ} \mathrm{C}$. Emulsion stabilized with (a) $5 \%(\mathrm{w} / \mathrm{w})(\mathrm{b}) 6 \%(\mathrm{w} / \mathrm{w})(\mathrm{c}) 7 \%(\mathrm{w} / \mathrm{w})$ 

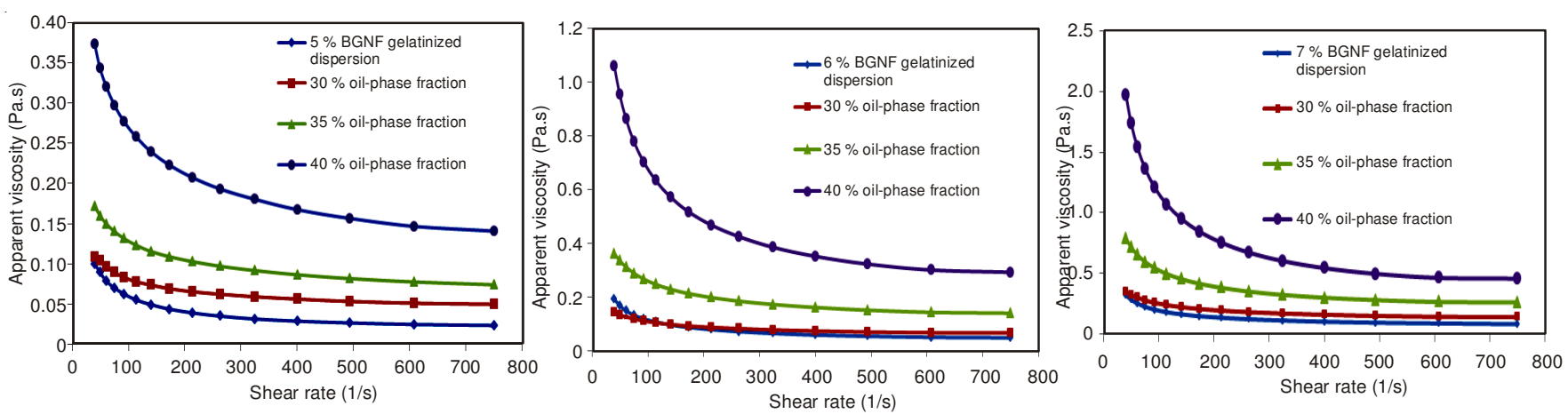

Fig. 6. Influence of oil-phase concentration on the apparent viscosity of the emulsions stabilized by gelatinized bambara groundnut flour (a) $5 \%$ bambara groundnut flour, (b) $6 \%$ bambara groundnut flour and (c) $7 \%$ bambara groundnut flour

in agreement with the report of researchers that apparent viscosities of emulsions increased with oil concentration ${ }^{37,38}$. Emulsions of flocculated droplets tend to exhibit a pronounced shear thinning behaviour since the hydrodynamic forces generated at low shear stresses may possibly not be large enough to disrupt the flocs and as such the agglomerates could behave like drops of a fixed size and shape resulting in a constant viscosity $^{2}$. Furthermore the flow curves of all the studied emulsions showed a relatively constant viscosity at high shear rates. This could be because all of the flocs are completely disrupted or the number of flocculated droplets remains constant since the rate of flocs formation is equal to the rate of flocs disruption at equilibrium ${ }^{2,39}$. The influence of bambara groundnut flour concentration on the rheological properties is shown in Fig. 6. There was a significant increase in apparent viscosities with an increased bambara groundnut flour concentration. This may be probably linked to the flow behaviours of their respective continuous phases having different bambara groundnut flour concentrations (Fig. 5). Although they contained the same concentration of oil, the increased concentration of the bambara groundnut flour in the formulations made the emulsion of higher bambara groundnut flour to be less susceptible to breakdown by shear stress because more cross-links were formed as the concentration of bambara groundnut flour increased. Similar results were reported by researchers when investigating the effect of polysaccharide on emulsion rheology $y^{2,35}$. Therefore shear thinning behaviour of the studied emulsions is as a result of both oil droplet defloculation as the shear rate increased and non-Newtonian characteristics of the continuous phase.

\section{Modeling of flow behaviour of $\mathrm{o} / \mathrm{w}$ emulsion stabilized with gelatinized bambara groundnut flour}

Herschel-Bulkley model: Herschel-Bulkley (H-B) model was developed to originally accommodate the poor result given by Ostwald-De Weale model at extremely low shear rate ${ }^{40}$. The model is appropriate for many fluid foods ${ }^{24,41}$. HerschelBulkley model is suitable for fluids that combine power law and Bingham characteristics. The mathematical expression of the model is in eqn. 2. If the yield stress of sample is known from an independent experiment, the consistency index $(\mathrm{K})$ and flow behaviour (n) can be obtained from linear regression of $\log \left(\tau-\tau_{0}\right) v s . \log (\gamma)$ as the intercept and slope respectively, alternatively, nonlinear regression technique can be used to estimate $\tau_{0}, \mathrm{~K}$ and $\mathrm{n}^{42}$. Herschel-Bulkley model parameters are as presented in Table-1. The coefficients of determination $\left(\mathrm{R}^{2}\right)$ were high indicating a high level of correlation between the experimental and predicted rheological data. Quantification by Herschel-Bulkley model showed that the entire emulsions studied possessed yield stresses between 0.8942-2.1766 Pa and increased as the concentration of oil $(\Phi)$ and bambara groundnut flour increased. Apparent yield stress has been interpreted as the applied stress that must be exceeded in order to make a structured fluid to flow ${ }^{43}$ and it is a significant factor in many industrial processes such as pumping, spreading and coating. Yield stress could however be desirable in some product design where the purpose is to keep the particles suspended in the medium. The mean consistency coefficient of all the emulsion ranged from 0.2291-9.8332 Pasn while the flow behaviour index was between $0.5239-0.7745$. The emulsion systems became more structured (as indicated by observed

TABLE-1

HERSCHEL-BULKLEY MODEL PARAMETERS FOR THE EMULSION STABILIZED BY BAMBARA GROUNDNUT FLOUR

\begin{tabular}{|c|c|c|c|c|c|c|}
\hline Oil-phase fraction & $\tau(\mathrm{Pa})$ & $\mathrm{K}\left(\mathrm{Pa} \cdot \mathrm{s}^{\mathrm{n}}\right)$ & $\mathrm{n}$ & $\mathrm{R}^{2}$ & RMSE & SE \\
\hline \multicolumn{7}{|c|}{5 (\%) Bambara groundnut flour } \\
\hline 30 & $0.9239 \pm 0.1783$ & $0.2291 \pm 0.1266$ & $0.7745 \pm 0.0820$ & 0.9998 & 0.1296 & 0.1341 \\
\hline 35 & $0.9566 \pm 0.0938$ & $0.3885 \pm 0.0954$ & $0.7479 \pm 0.0398$ & 0.9998 & 0.0846 & 0.0876 \\
\hline 40 & $1.0264 \pm 0.0023$ & $1.0673 \pm 0.0314$ & $0.6902 \pm 0.0071$ & 0.9995 & 0.5918 & 0.6125 \\
\hline \multicolumn{7}{|c|}{$6(\%)$ Bambara groundnut flour } \\
\hline 30 & $0.8942 \pm 0.0107$ & $0.3050 \pm 0.0807$ & $0.7634 \pm 0.0398$ & 0.9993 & 0.3399 & 0.3518 \\
\hline 35 & $1.0142 \pm 0.0027$ & $0.9400 \pm 0.0407$ & $0.7064 \pm 0.0129$ & 0.9983 & 1.1032 & 1.1419 \\
\hline 40 & $1.2882 \pm 0.0137$ & $4.4707 \pm 0.1585$ & $0.5796 \pm 0.0047$ & 0.9943 & 3.8488 & 3.9839 \\
\hline \multicolumn{7}{|c|}{$7(\%)$ Bambara groundnut flour } \\
\hline 30 & $1.0016 \pm 0.0039$ & $0.8257 \pm 0.0464$ & $0.7258 \pm 0.0143$ & 0.9977 & 1.2718 & 1.3164 \\
\hline 35 & $1.1218 \pm 0.0036$ & $2.4375 \pm 0.0416$ & $0.6545 \pm 0.0035$ & 0.9948 & 3.4271 & 3.5474 \\
\hline 40 & $2.1766 \pm 0.3265$ & $9.8332 \pm 0.5573$ & $0.5239 \pm 0.0023$ & 0.9844 & 9.3322 & 9.6598 \\
\hline
\end{tabular}




\begin{tabular}{|c|c|c|c|c|c|}
\hline \multicolumn{6}{|c|}{$\begin{array}{c}\text { TABLE-2 } \\
\text { CASSON MODEL PARAMETERS FOR THE EMULSION STABILIZED WITH BAMBARA GROUNDNUT FLOUR }\end{array}$} \\
\hline Oil-phase fraction & $\tau_{\mathrm{oc}}^{0.5}(\mathrm{~Pa})^{0.5}$ & $\mathrm{~K}(\mathrm{~Pa} \cdot \mathrm{s})^{0.5}$ & $\mathrm{R}^{2}$ & RMSE & SE \\
\hline \multicolumn{6}{|c|}{$5(\%)$ BGNF Concentration } \\
\hline 30 & $0.9495 \pm 0.1504$ & $0.1892 \pm 0.0059$ & 0.9996 & 0.0243 & 0.0251 \\
\hline 35 & $1.2688 \pm 0.0405$ & $0.2293 \pm 0.0013$ & 0.9985 & 0.0564 & 0.0584 \\
\hline 40 & $2.1333 \pm 0.0108$ & $0.30140 \pm 0.0040$ & 0.9974 & 0.0977 & 0.1011 \\
\hline \multicolumn{6}{|c|}{$6(\%)$ BGF Concentration } \\
\hline 30 & $1.0936 \pm 0.0606$ & $0.2171 \pm 0.0063$ & 0.9991 & 0.0411 & 0.0426 \\
\hline 35 & $2.0586 \pm 0.0255$ & $0.2988 \pm 0.0078$ & 0.9998 & 0.0701 & 0.0726 \\
\hline 40 & $4.3366 \pm 0.1012$ & $0.3790 \pm 0.0131$ & 1.0000 & 0.1180 & 0.1221 \\
\hline \multicolumn{6}{|c|}{$7(\%)$ BGNF Concentration } \\
\hline 30 & $1.9428 \pm 0.0448$ & $0.3019 \pm 0.0081$ & 0.9999 & 0.0593 & 0.0614 \\
\hline 35 & $3.3344 \pm 0.0538$ & $0.3841 \pm 0.0036$ & 0.9999 & 0.0876 & 0.0907 \\
\hline 40 & $6.3215 \pm 0.2575$ & $0.4309 \pm 0.0100$ & 0.9968 & 0.1586 & 0.1641 \\
\hline
\end{tabular}

increase in consistency coefficient) with an increase in oil and bambara groundnut flour concentrations. This could as well be attributed to stronger interaction between oil particles as the oil concentration increases and the non-Newtonian effect of the continuous GBGFD. Similarly the flow behaviour indexes were observed to decrease as the oil concentration and bambara groundnut flour concentration increased. This may also be due to the systems becoming more and more flocculated as the components increased.

Casson model: The Casson model had been reported to apply widely in the range of food products ${ }^{25}$. Casson model are closely related with the effect of particle size distribution on the flow behaviour of pigment-oil suspensions ${ }^{44}$. There are two parameters determined from Casson model, namely Casson yield $\tau_{\mathrm{oc}}^{0.5}$ and the Casson plastic viscosity k. Casson model parameters are tabulated in Table-2. The coefficient of determination $\mathrm{R}^{2}$ value obtained for all the emulsions is relatively higher $(R>0.995)$. All the emulsion samples exhibited definite yield stress due to significant particle-particle interactions throughout the range of bambara groundnut flour and oil-phase concentration studied. It can be seen from Table2 that Casson yield stress and Casson plastic viscosity ranged from 0.9495-6.3215 $\left(\mathrm{Pa}^{0.5}\right)$ and 0.1892-0.4309 $\left(\mathrm{Pas}^{0.5}\right)$, respectively and increased as the bambara groundnut flour and oil concentration increased.

Comparison of selected rheological models: The coefficient of determination for both rheological flow models was close to unity. This is an indication that they can both perfectly predict the flow behaviour of the sunflower oil-gelatinized bambara groundnut flour emulsion systems within the range of shear rate studied. However, the root mean square error and standard error (SE) values for Casson model are lower than the corresponding prediction of the Herschel-Bulkley model and also the observed $\mathrm{R}^{2}$, was higher for all predictions of Casson model than the other tested model. Hence, Casson model is a better predictor within the studied range of bambara groundnut flour and oil-phase concentrations.

\section{Conclusion}

Sunflower-oil-in-water emulsion was stabilized using gelatinized bambara groundnut flour dispersions. Both the bambara groundnut flour and sunflower oil concentrations have noticeable influence on the particle size and particle size distri- bution. Storage stability using Turbiscan M.A 2000 revealed that the emulsion components (bambara groundnut flour and sunflower oil concentration) affect emulsion stability. Steady state flow curves of the continuous phase (gelatinized bambara groundnut flour dispersions) and emulsion showed shear thinning characteristics. Increase in oil-particles and bambara groundnut flour concentration caused an increase in apparent viscosity of the emulsion systems. The pseudoplastic nature of the emulsions was as a result of both oil-particle deflocculation as the shear rate increased and the non-Newtonian nature of the gelatinized bambara groundnut flour. Both tested rheological models can reasonably predict steady shear behaviour of emulsions stabilized with bambara groundnut flour. Fitting of rheological data to Herschel-Bulkley and Casson models revealed that all bambara groundnut flour emulsion samples possessed yield stress which increased as the bambara groundnut flour and oil phase concentration increased. However, Casson model was a better predictor because of its relatively higher coefficient of determination $\left(\mathrm{R}^{2}\right)$ values and lower values of root mean square error (RMSE) and standard error (SE) between the experimental and predicted points. Bambara groundnut therefore showed a great potential in food applications if properly engineered.

\section{REFERENCES}

1. D.J. McClements, Food Emulsions, Principles, Practice and Techniques. LLC: CRC Press (1999).

2. V. Samavati, Z. Emama-Djomeh, M.A. Mohammadifar, M. Omid and A.L.I. Mehdinia, J. Texture Stud., 1, 14 (2011).

3. R. Pal, Chem. Eng. Sci., 5, 3299 (1995).

4. R. Chanamai and D.J. McClements, Colloids Surf. A, 172, 79 (2000).

5. D.R. Izidoro, A. Scheer and M. Sierakowski, Braz. J. Biol., 52, 1516 (2009).

6. N. Georgiadis, C. Ritzoulis, G. Sioura, P. Kornezou, C. Vasiliadou and C. Tsioptsias, Food Hydrocoll., 25, 991 (2011).

7. B. Wang, D. Li, L. Wang and N. Ozkan, J. Food Eng., 96, 555 (2010).

8. K.O. Adebowale and O.S. Lawal, Nahrung/Food, 46, 311 (2002).

9. N.H. Poulter and J.C. Caygill, J. Sci. Food Agric., 31, 1158 (1980).

10. O.M. Bamishaiye, J.A. Adeghola and E.I. Bamishaiye, Adv. Agric. Biotechnol., 1, 60 (2011).

11. J. Okpuzor, H.A. Oghunugafor, U. Okafor and M.O. Sofidiya, EXCLI J., 9, 17 (2010).

12. P. Sirivongpaisal, Songlanakarin J. Sci. Technolol, 30, 51 (2008).

13. A.A. Yusuf, H. Ayedun and L.O. Sanni, Food Chem., 111, 277 (2008).

14. D.J. McClements and J. Weiss, Lipid Emulsions, Bailey's Industrial Oil and Fat Products (2005).

15. G. Lorenzo, N. Zaritzky and A. Califano, Food Res. Int., 41, 487 (2008). 
16. S. Kondaraju, H. Farhat and J.S. Lee, Soft Matter, 8, 1374 (2012).

17. S. Caubet, Y. Le Guer, B. Grassl, K. El Omari and E. Normandin, AlChe J., 57, 27 (2011).

18. F.A. Perrechil and R.L. Cunha, J. Food Eng., 97, 441 (2010).

19. P. Bellalta, E. Troncoso, R.N. Zuniga and J.M. Aguilera, LWT-Food Sci. Technol., 46, 375 (2012).

20. R.E. Walpole, R.H. Myers, S.L. Myers and K. Ye, Probability and Statistics for Engineers and Scientists, Prentice Hall, New Jersey, edn 7 (2002).

21. N.L. Chin, S.M. Chan, Y.A. Yusof, T.G. Chuah and R.A. Talib, J. Food Eng., 93, 134 (2009).

22. C.I. Nindo, J. Tang, J.R. Powers and P.S. Takhar, LWT-Food Sci. Technol., 40, 292 (2007).

23. S. Keshani, C. Luqman and A.R. Russly, Int. Food Res. J., 19, 553 (2012).

24. S.D. Holdsworth, Trans. Inst. Chem. E, 71, 139 (1993).

25. Y. Gu, E. Decker and D.J. McClements, Langmuir, 21, 5752 (2005).

26. N. Camino and A.M.R. Pilosof, Food Hydrocoll., 25, 1051 (2011).

27. G.G. Palazolo, D.A. Sorgentini and J.R. Wagner, Food Hydrocoll., 19, 595 (2005).

28. A.L. Marquez, G.G. Palazolo and J.R. Wagner, Grasas y Aceites, 56 59 (2005).

29. M.S. Álvarez Cerimedo, C.H. Iriart, R.J. Candal and M.L. Herrera, Food Res. Int., 43, 1482 (2010).

30. W. Prinyawiwatkul, L.R. Beuchat, K.H. McWatters and R.D. Phillips, J. Agric. Food Chem., 45, 480 (1997)
31. M.A. Rao, P.E. Okechukwu, J.C. Da Silva and J.C. Oliveira, Carbohydr. Polym., 33, 273 (1997).

32. C.G. Mothé, A.D. Azevedo and R. Antoniassi, Rheological Characterization of Emulsions from Soymilk, 3rd International Symposium on Food Rheology and Structure, pp. 531-532 (2011).

33. M. Alpaslan and M. Hayta, J. Food Eng., 54, 89 (2002).

34. P. Sherman, Rheological Properties of Emulsions, Encyclopedia of Emulsion Technology, vol. 1, p. 405 (1983)

35. A.R. Taherian, P. Fustier and H.S. Ramaswamy, J. Food Eng., 77, 687 (2006).

36. U. Klinkesorn, P. Sophanodora, P. Chinachoti and D.J. McClements, Food Res. Int., 37, 851 (2004).

37. C. Sun and S. Gunasekaran, Food Hydrocoll., 23, 165 (2009).

38. J.E. Moros, J.M. Franco and C. Gallegos, Int. J. Food Sci. Technol., 37, 297 (2002).

39. O.H. Campanella, N.M. Dorward and H. Singh, J. Food Eng., 25, 427 (1995).

40. M. Khalil and B. Mohamed Jan, J. Appl. Polym. Sci., 124, 595 (2012).

41. J. Ahmed, Int. J. Food Sci. Technol., 39, 325 (2004).

42. M.A. Rao and H.J. Cooley, J. Food Process Eng., 6, 159 (1983).

43. J.F. Steffe, Rheological Methods in Food Process Engineering, Freeman Press, East Lansing, MI, USA, edn 2 (1996).

44. T.G. Chuah, H. Hairul Nisah, S.Y. Thomas Choong, N.L. Chin and A.H. Nazimah Sheikh, J. Food Eng., 80, 423 (2007). 